\section{Remote viewing exposed}

SIR-Some years ago, we challenged experiments on remote viewing conducted by Targ and Puthoff' on the grounds that sensory cues were available to the judges, enabling correct matching of the subjects' descriptions against the target locations ${ }^{2}$. This objection was countered when another investigator, Tart, attempted to remove all the cues and organized a rejudging that yielded results as significant as those originally obtained ${ }^{3}$. At this stage, we asked for access to the data, and we are now pleased to acknowledge that, after a three-year interval, Puthoff has released the relevant data from the first experimental series with the subject Price. Having examined both the edited and unedited transcripts, we note that Tart failed to remove a number of potentially useful cues from the transcripts given to his judge. This bias in Tart's editing, as was suspected earlier ${ }^{4}$, invalidates the judging exercise.

The Price series of remote viewings consisted of nine experiments. Eight of the allegedly edited transcripts (all except the one from Experiment 2) retain information concerning the subject's location. These were a park in Experiments 1 and 2, an office in Experiment 5, and a shielded room in the remainder of the experiments. The transcript for Experiment 1 also retains the passage at the very beginning where Price expresses apprehension about being able to perform the task: "the feeling that one can't or won't be able to do it and shouldn't even try it". The transcript from Experiment 3, the first to be conducted inside the shielded room, quotes a question from Targ as to whether the subject noticed "any difference in being in a shielded room compared to being in the park".

Targ and Puthoff's publication MindReach ${ }^{5}$ contains extracts from the transcripts for Experiments 1, 4 and 9 and publishes in full the transcript for Experiment 7. Mind-Reach also lists the correct order of target sites and the subject's location during each of the experiments. Given the public availability of MindReach at the time when the rejudging was conducted, it was not a valid procedure to include all nine of the transcripts, as the judge could easily look up the relevant information or recall it using memory based upon earlier reading of the material. Only the five targets not cued by the information in Mind-Reach should have been employed (Experiments 2, 3, 5, 6 and 8 ) as in the case of the unsuccessful rejudging reported by Marks and Kammann ${ }^{2}$ which used transcripts with all cues deleted. Furthermore, the cues contained in the transcripts associated with Experiments 1 and 3 invalidate the inclusion of Experiments 1, 2 and 3 as the transcripts

London N19, UK for all three of these experiments can be readily matched using the available cues. Experiment 5 is also invalidated because its transcript contains the uniquely diagnostic cue of the subject's location (an office) used only on this occasion. Hence only Experiments 6 and 8 remain potentially uncued in the rejudging exercise.

Considering the importance for the remote viewing hypothesis of adequate cue removal, Tart's failure to perform this basic task seems beyond comprehension. As previously concluded ${ }^{2}$, remote viewing has not been demonstrated in the experiments conducted by Puthoff and Targ, only the repeated failure of the investigators to remove sensory cues.

David Marks

Department of Psychology,

University of Otago,

Dunedin, New Zealand

60 Highgate Hill,

1. Targ, R. \& Puthoff, H. Nature 251, 602-607 (1974)

2. Marks, D. \& Kammann, R. Nature 274, 680-681 (1978)

3. Tart, C.T., Puthoff, H. \& Targ, R. Nature 284, 191 (1980)

4. Marks, D. Nature 292, 177 (1981).

Targ, R. \& Puthoff, H. Mind-Reach (Delacorte, New York 1977)

\section{No sexism please}

SIR-Gerald Weissmann, in his zeal to defend the University of Texas Health Services Center (Nature 318, 308; 1985), appears to have committed a gaffe of his own. Presumably "daughters" as well as "sons" of the university will be future Nobel laureates, assuming that the university employs both male and female scientists.

AnN S. HobBs

Department of Physiology,

University of Maryland,

School of Medicine,

660 West Redwood Street,

Baltimore, Maryland 21201, USA

\section{Future UNESCO}

SIR-Whatever the reasons for the withdrawal of the United States and Britain from UNESCO, such drastic action is needed in my opinion to dismantle an institution that has sunk into a vicious circle of rot. UNESCO is not the only UN agency that needs stripping; others also suffer innumerable faults in their operation. The United Nations embodies the highest ideals of mankind and if its scientific agencies are to function with minimum errors and deviations, then they should be serviced by the highest calibre of scientists, not by those whose prime motives are in financial reward and political glory.

Your leading article $(\mathbf{3 1 8}, 397 ; 1985)$ omits a dire consequence that may result from the departure of Britain from
UNESCO - the export of inferior values in science and education to the Englishspeaking developing countries in Africa by those who are probably eager to step into the niche left by the departing British. Modest but good and useful science was established by the British in their former colonies. The high quality of relevant environmental sciences in East Africa before and for about a decade after the independence of these countries is one such example. Subsequently, scientific research in these countries declined. Now, I cannot help thinking of the possible infiltration into these countries of what I see as "science without its scientific ethics", and the threat that this would pose to the further decay and distortion of the image of science in these countries.

43 Margaret Street,

Walkerville,

South Australia 5081

\section{Catastrophism}

SiR-I refer to Paul R. Weissman's letter (Nature 316, 572; 1985) "Catastrophism still unexplained", and the 1978 and 1979 references.

The suggestion that the Sun's motion in the Galaxy might be a possible cause of terrestrial extinctions was made by $\mathrm{J}$. Steiner as early as $1967^{\prime}$ and again, independently, by A.A. Meyerhoff in $1973^{2}$, though these references suggest the Sun's intragalatic orbit as the cause of the 250million-year cycle if it exists.

W. Stannage

5 Coastguard Station,

Robin Hood Bay,

North Yorkshire YO22 4SY, UK

1. Steiner, J. J. geol. Soc. Aust. 14 (1), 99 (1967).

2. Meyerhoff, A.A. Can. Soc. Petrol. Geol. Memoir 2, 745 (1973).

\section{Eureka!}

SiR-Buckminsterfullerene is not only a clumsy name for an outstandingly beautiful molecule (Nature 318, 162-164; 1985); it is also historically inappropriate. The truncated icosahedron was known to the First Century Alexandrian mathematicians Heron and Pappos, who refer to a text on this and a dozen other such solids by Archimedes. The original treatise has since been lost, but it would be a fitting tribute to call the new substance Archimedene. This could be abbreviated to Archene (particularly suitable if this should indeed turn out to be one of the oldest molecules in the Universe - Greek arkhe 'origin'), or ARCH (all-round carbohedron).

University of $O x$ ford,

Philip J. STewart

Pauling Human Sciences Centre,

58 Banbury Road,

Oxford OX2 6QS, UK 